\title{
COMPARISON OF OPEN MESH HERNIOPLASTY WITH LAPAROSCOPIC TOTAL EXTRAPERITONEAL (TEP) MESH REPAIRS FOR INGUINAL HERNIAS.
}

\footnotetext{
1. MBBS, FCPS General Surgery Senior Registrar Department of Surgery Allied Hospital, Faisalabad.

2. MBBS, MD

Resident IM/PM

Griffin Hospital, Derby

Connecticut USA.

3. MBBS, FCPS General Surgery

Senior Registrar

Department of Surgery

Allied Hospital, Faisalabad.

4. MBBS, FCPS

Assistant Professor

Department of Surgery

Allied Hospital, Faisalabad.

5. MBBS, MRCS, FCPS

Senior Registrar

Department of Surgery

Allied Hospital, Faisalabad.

6. MBBS, FCPS

Associate Professor

Department of Surgery

Allied Hospital, Faisalabad.
}

Correspondence Address:

Dr. Muhammad Usman

Department of Surgery

Allied Hospital, Faisalabad.

doctor_usman@hotmail.com

Article received on:

01/03/2018

Accepted for publication:

22/01/2019

Received after proof reading:

25/06/2019

\section{INTRODUCTION}

Inguinal hernia is one of the most frequently performed surgical procedure worldwide with an estimated 800,000 cases per year in the United States alone, and 20 million procedures across the globe annually. ${ }^{1,2,3,4}$ Inguinal hernia repair consumes an important part of health care resources because of the high incidence of the problem. Inguinal hernia repair is probably the field where the surgeons have most variable alternatives in general surgery. ${ }^{5}$

There are many different techniques for the repair of inguinal hernias. Inguinal hernia repair has been evolving for the past 130 years and the pace of evolution accelerated by the introduction of the open mesh repair technique for an inguinal hernia by Lichtenstein in $1986 .{ }^{6}$ The Lichtenstein technique has since become the frequently used (with various modifications) on account of its easiness and as it provides a tension-free repair with good long-term results. Tension-free mesh repair is, however, associated with complications such as a foreign body reaction, infection, pain, fistula formation, migration, shrinkage, and recurrence. ${ }^{7}$

Laparoscopic hernia repair was first described in 1982. There are two basic laparoscopic techniques, trans-abdominal pre-peritoneal (TAPP) and total extraperitoneal (TEP). ${ }^{8}$ Of laparoscopic procedures employed today, the totally extraperitoneal approach (TEP) is recommended by European hernia society rather than transabdominal (TAPP). ${ }^{9}$ Laparoscopic repair of an inguinal hernia is a recent advancement, 
although less conventional, but shows low recurrence rate, less postoperative pain, early recovery and return to work, low rate of early and late complications. ${ }^{10}$ Despite the wide interest that has been gained in laparoscopic inguinal hernia repair, this approach as a gold standard treatment for inguinal hernia repair has not yet been accepted. ${ }^{11}$

Different studies show contradictory results about the effectiveness of Lichtenstein technique and TEP. For instance Kirshan Lal's study stated that TEP is better than Lichtenstein technique in terms of development of scrotal hematoma $(1.9 \%$ and $12.2 \%$, respectively) ${ }^{8}$, another study stated that there is an equal chance of development of scrotal hematoma in both Lichtenstein technique and TEP (9\% and $10 \%$ respectively)..$^{12}$

Inguinal hernia repair is the most frequently performed operations in general surgery. The results of the above-mentioned studies show controversy in terms of preferred technique of repair. So, this study was conducted to evaluate the technique with better efficacy that will be offered to the patients in the future.

\section{OBJECTIVE}

The objective of this study was to compare the outcome of open mesh hernioplasty (Lichtenstein technique) with laparoscopic total extraperioneal (TEP) mesh repairs for the treatment of inguinal hernias.

\section{MATERIALS AND METHODS}

This study was a randomized controlled trial conducted at the Department of Surgery, Allied Hospital, Faisalabad, Pakistan from 7th February 2014 to 6th August 2014. Total 154 patients were enrolled in two groups (77 in each group) using purposive, non-probability sampling. Patients of age 20-45 years of both genders with an inguinal hernia were included in the study. Recurrent and bilateral inguinal hernia patients were also included in the study. Exclusion criteria include the Patients found unfit for general anesthesia or laparoscopic surgery (INR > 1.5); History of chronic or persistent cough; History of previous abdominal surgeries and Presentation of any infective lesion at or around the site of the incision.

After taking approval from hospital ethical committee, patients coming through OPD (out patient department) fulfilling the inclusion criteria was enrolled and informed consent was taken. Patients were randomly allocated by computer generated random number table in two equal groups: 77 patients in group A underwent laparoscopic hernioplasty and 77 patients in group B underwent open hernioplasty. The principle operative technique was total extraperitoneal repair in the laparoscopic group and Lichtenstein's repair in open group. Both the procedures were performed by the same team of surgeons.

The primary outcome, i.e. scrotal hematoma (swelling of the scrotum) was assessed clinically and thepresence of blood in the scrotum was confirmed by ultrasound by the radiologist. Each patient was followed for 15 days. All the information was collected on a specially designed proforma and analyzed by using SPSS version 16. Descriptive statistics including mean and standard deviation of numeric values like age was evaluated. The presence of scrotal hematoma was presented as frequency and percentage and it was compared by using chi-square test between both groups. Effect modifiers like age were controlled by stratification. Post-stratification chi-square test was applied. p-value less than 0.05 was considered significant.

\section{RESULTS}

A total of 154 patients with an inguinal hernia were included in the study and randomly divided into 2 groups. Group A was laparoscopic total extra peritoneal mesh repair while group B was open mesh hernioplasty.

Out of 154 patients, mean age of the patients was $32.91 \pm 7.78$ years. In group $A$, out of 77 patients mean age of the patients was $31.96 \pm 7.28$ years. In group $B$, out of 77 patients mean age of the patients was $33.86 \pm 8.18$ years. Stratification for age groups is shown in Table-I.

In group A, 46 (59.7\%) patients had right sided 
inguinal hernia, $23(29.9 \%)$ patients had left sided inguinal hernia and $8(10.4 \%)$ patients had bilateral inguinal hernia. In group B, 41 (53.2\%) patients had right sided inguinal hernia, 29 $(37.7 \%)$ patients had left sided inguinal hernia and $7(9.1 \%)$ patients had bilateral inguinal hernia ( $p$-value $=0.593$ ).

In group A, 34 (44.2\%) had direct inguinal hernia while 43 (55.8\%) patients had an indirect inguinal hernia. In group B, 24 (31.2\%) had direct inguinal hernia and $53(68.8 \%)$ patients had an indirect inguinal hernia ( $p$-value $=0.096$ ). In group $A$, recurrent hernia was present in 18 (23.4\%) patients while in group B it was founded in 24 $(31.2 \%)$ patients ( $p$-value $=0.278$ ).

Out of 154 patients, scrotal hematoma was present in $15(9.7 \%)$ patients. In group A, scrotal hematoma was present in $3(3.9 \%)$ patients, whereas in group B, it was found in 12 (15.6\%) patients $(p$-value $=0.014)($ Table-II).

In group A, scrotal hematoma was present in 1 $(2.9 \%)$ patients having direct inguinal hernia while $2(4.7 \%)$ patients withan indirect inguinal hernia. In group $B$, scrotal hematoma was present in 5 $(20.8 \%)$ patients having direct inguinal hernia while $7(13.2 \%)$ patients withan indirect inguinal hernia $(p$-value $=0.799)($ Table-III).

In group $A$, no scrotal hematoma was found in patients with recurrent inguinal hernia while in group B, scrotal hematoma was found in 3 $(12.5 \%)$ patients having arecurrent inguinal hernia $(p$-value $=0.379)($ Table-IV $)$.

\begin{tabular}{|c|c|c|c|}
\hline $\begin{array}{c}\text { Age distribution } \\
\text { Variable }\end{array}$ & $\begin{array}{c}\text { Laparoscopic Total Extraperitoneal } \\
\text { Mesh Repair }\end{array}$ & Open Mesh Hernioplasty & Total \\
\hline $\mathbf{2 1 - 2 5}$ & $22(28.6 \%)$ & $16(20.8 \%)$ & $38(24.7 \%)$ \\
\hline $\mathbf{2 6 - 3 0}$ & $23(29.9 \%)$ & $22(28.6 \%)$ & $45(29.2 \%)$ \\
\hline $\mathbf{3 1 - 3 5}$ & $3(3.9 \%)$ & $1(1.3 \%)$ & $4(2.6 \%)$ \\
\hline $\mathbf{3 6 - 4 0}$ & $9(11.7 \%)$ & $12(15.6 \%)$ & $21(13.6 \%)$ \\
\hline $\mathbf{4 1 - 4 5}$ & $20(26.0 \%)$ & $26(33.8 \%)$ & $46(29.9 \%)$ \\
\hline Total & 77 & 77 & 154 \\
\hline
\end{tabular}

\begin{tabular}{|l|c|c|c|}
\hline \multirow{2}{*}{$\begin{array}{c}\text { Scrotal } \\
\text { Hematoma }\end{array}$} & $\begin{array}{c}\mid c \\
\text { Group }\end{array}$ & Total \\
\hline Yes & $\begin{array}{c}\text { Laparoscopic Total Extraperitoneal Mesh } \\
\text { Repair }\end{array}$ & Open Mesh Hernioplasty & \\
\hline No & $3(3.9 \%)$ & $12(15.6 \%)$ & $15(9.7 \%)$ \\
\hline Total & $74(96.1 \%)$ & $65(84.4 \%)$ & $139(90.3 \%)$ \\
\hline
\end{tabular}

Table-II. Scrotal hematoma among both groups p-value $=0.014$

\begin{tabular}{|c|c|c|c|c|c|}
\hline \multicolumn{6}{|c|}{ Group } \\
\hline \multirow{3}{*}{ Scrotal Hematoma } & \multirow{2}{*}{\multicolumn{2}{|c|}{$\begin{array}{c}\text { Laparoscopic Total Extraperitoneal Mesh } \\
\text { Repair } \\
\text { Type of Hernia }\end{array}$}} & \multirow{2}{*}{\multicolumn{2}{|c|}{$\begin{array}{l}\text { Open Mesh Hernioplasty } \\
\text { Type of Hernia }\end{array}$}} & P-Value \\
\hline & & & & & \multirow{5}{*}{0.799} \\
\hline & Direct & Indirect & Direct & Indirect & \\
\hline Yes & $1(2.9 \%)$ & $2(4.7 \%)$ & $5(20.8 \%)$ & $7(13.2 \%)$ & \\
\hline No & $33(97.1 \%)$ & $41(95.3 \%)$ & $19(79.2 \%)$ & $46(86.8 \%)$ & \\
\hline Total & 34 & 43 & 24 & 53 & \\
\hline
\end{tabular}




\begin{tabular}{|c|c|c|c|c|c|}
\hline \multicolumn{6}{|c|}{ Group } \\
\hline \multirow{2}{*}{ Scrotal Hematoma } & \multicolumn{2}{|c|}{$\begin{array}{c}\text { Laparoscopic Total Extraperitoneal Mesh } \\
\text { Repair } \\
\text { Recurrent Hernia }\end{array}$} & \multicolumn{2}{|c|}{$\begin{array}{c}\text { Open Mesh Hernioplasty } \\
\text { Recurrent Hernia }\end{array}$} & P-Value \\
\hline & Yes & No & Yes & No & \multirow[b]{2}{*}{0.568} \\
\hline Yes & 0 & $3(5.1 \%)$ & 3 (12.5\%) & 9 (17\%) & \\
\hline
\end{tabular}

Table-IV. Scrotal hematoma among both groups according to recurrent hernia

\section{DISCUSSION}

The history of treating groin hernias has evolved from life-saving procedures for a strangulated hernia in the past to elective short stay surgery for uncomplicated hernias today.

The Lichtenstein repair is currently the most appropriate operation for primary inguinal hernias. It is associated with an excellent outcome in the hands of non-specialist surgeons and results in less postoperative pain and early return to normal activities when compared with suture repairs. ${ }^{7}$

Laparoscopic total extra peritoneal repair has established itself as a favored procedure with comparable results to open surgery and is set to become the future standard of care. ${ }^{13,14}$ However, the laparoscopic hernia repair has been criticized for technical difficulties, cost, and a long learning curve. ${ }^{15,16}$ The indications for laparoscopic hernia repair have been debated. ${ }^{17}$ Many of the publications that have been the foundation for the debate have been studies using the trans abdominal preperitoneal (TAPP) technique in a randomized design compared with a conventional open repair with or without mesh. ${ }^{18}$ In the present study, we used TEP since it does not involve entering the abdominal cavity.

The results of this study revealed that the majority of the patients belong to the age of 26-30 (29.2\%) and $41-45$ years $(29.9 \%)$. Recurrent hernia was found in $27.3 \%$ (23.4\% in TEP group and $31.2 \%$ in the open mesh group). Indirect hernia was found to be in $62.3 \%$ (55.8\% in TEP group and $68.8 \%$ in the open mesh group) and in most of the cases $56.5 \%(59.7 \%$ in TEP group and $53.2 \%$ in the open mesh group) inguinal hernia was present on the right side. In laparoscopic total extraperitoneal mesh repair, scrotal hematoma was found to be in $3.9 \%$ while in open mesh hernioplasty it was in $15.6 \%$.

Krishan Lal et al ${ }^{8}$ conducted a study in Jamshoro on the comparison of laparoscopic total extra peritoneal mesh repair and open mesh hernioplasty. They observed that the majority of the patients $(53 \%)$ belongs to $41-55$ years of age. The indirect hernia was present in $67 \%$ in laparoscopic total extra peritoneal mesh repair group and $64.9 \%$ in open mesh hernioplasty. Right sided hernia is more common $(40.3 \%$ in laparoscopic total extra peritoneal mesh repair group and $61.4 \%$ in open mesh hernioplasty group. The scrotal hematoma was found to be in $1.9 \%$ patients in laparoscopic total extra peritoneal mesh repair group while $12.2 \%$ in open mesh hernioplasty. They concluded that laparoscopic total extra peritoneal mesh repair is the best option of treatment for are current and bilateral hernia which favors the results of our study.

Bringman $S$ et $\mathrm{al}^{17}$ conducted a study on the comparison of laparoscopic TEP, Mesh plug, and Lichtenstein procedure. They observed that the hematoma was present in 3.3\% patients in TEP group and $7.8 \%$ patients in Lichtenstein group. They concluded that laparoscopic TEP is superior to Lichtenstein and mesh plug techniques in terms of postoperative complications and rehabilitation. These results are comparable to our study.

Meta-analyses revealed that laparoscopic and open mesh repairs for recurrent inguinal hernias were equivalent in most of the analyzed outcomes. Fewer hematoma formations were observed in the laparoscopic group in comparison with the Lichtenstein group. ${ }^{19}$ 
Nadir SM, et al $^{7}$ conducted a study in Karachi about the efficacy of the Lichtenstein procedure for treatment of an inguinal hernia. The results of their study showed that the majority of the patients (31.25\%) belongs to an age range between 21-30 years. $75.89 \%$ patients had anindirect inguinal hernia. The hematoma was found in $6.2 \%$ patients. They concluded that the Lichtenstein repair procedure is a safe method with low postoperative complications.

Bhatti $\mathrm{N}$, et $\mathrm{al}^{20}$ conducted a study on the early outcome of laparoscopic TEP in Larkana, Pakistan. The study results showed that the hematoma was noticed in $2.4 \%$ patients. They concluded that laparoscopic TEP is a new and safe technique for inguinal hernia repair with acceptable rates of morbidity.

Recurrent and bilateral hernias are another specific issues. Laparoscopic techniques are good options for these cases. EHS recommends Lichtenstein and endoscopic repairs for these issues. ${ }^{21}$ Results of our study are also in favor of these recommendations.

In a study conducted by Chung et, $\mathrm{al}^{16}$ showed that most of the patients $(48.1 \%)$ presented with the right sided hernia. An indirect hernia was found to be in $64.3 \%$ patients. The hematoma was present in $3.6 \%$ patients in laparoscopic TEP hernioplasty and $5.4 \%$ patients in open mesh repair which shows both the techniques are equally effective in terms of postoperative complication i.e. hematoma which is against the results of our study.

Gürbulak EKet al ${ }^{11}$ concluded that the complications and recurrence rates and effects on testicular effusion and testicular volume in both laparoscopic and open techniques are similar, whereas the laparoscopic approach has shorter operative time than open hernia repair. So these results favor the laparoscopic technique is better than open technique.

Aly $\mathrm{O}$ et $\mathrm{al}^{12}$ conducted a systemic review at University of Aberdeen, U.K on a comparison of laparoscopic total extra peritoneal mesh repair and open mesh repair. They observed that scrotal hematoma was present in $10 \%$ patients in laparoscopic TEP group and $9 \%$ in open mesh hernioplasty. They concluded that both laparoscopic TEP and Lichtenstein repair are clinically effective procedures. The results of our study showed that laparoscopic TEP is better than Lichtenstein repair. The difference between the results of our study and above mentioned studies may be due to some technical difficulties faced by the surgeons.

\section{CONCLUSION}

Laparoscopic TEP can be performed safely with acceptable post-operative complication and is better treatment modality than open mesh hernioplasty. Laparoscopic TEP is also a better option of treatment for arecurrent and bilateral hernia. It can be used as the first line treatment for an inguinal hernia in future with less postoperative complication.

Copyright $\odot 22$ Jan, 2019.

\section{REFERENCES}

1. Sürgit Ö, Çavuşoğlu NT, Kılıç MÖ, Ünal Y, Koşar PN, İçen $D$. Use of fibrin glue in preventing pseudorecurrence after laparoscopic total extra peritoneal repair of large indirect inguinal hernia. Ann Surg Treat Res. 2016 Sep; 91(3):127-32. doi: 10.4174/astr.2016.91.3.127. Epub 2016 Aug 29. PubMed PMID: 27617253; PubMed Central PMCID: PMC5016602.

2. Reiner MA, Bresnahan ER. Laparoscopic total extra peritoneal hernia repair outcomes. JSLS. 2016 Jul-Sep; 20(3). pii: e2016.00043. doi: 10.4293/ JSLS.2016.00043. PubMed PMID: 27493471; PubMed Central PMCID: PMC4949355.

3. Bittner R, Schwarz J. Inguinal hernia repair: Current surgical techniques. Lagenbecks Arch Surg. 2012; 397:271-82.

4. Poelman MM, van den Heuvel B, Deelder JD, et al. EAES consensus development conference on endoscopic repair of groin hernias. Surg Endosc. 2013; 27:350519.

5. Genc V, Ensari C, Kulacoglu H, Ersoy E, Ergul Z. A questionnaire study on the surgeons preferences for inguinal hernia repair after a decade. J Coll Physicians Surg Pak. 2009; 19(11):744-6. 
6. Mahmood Z, Imran M, Shah TA. Results of open mesh hernioplasty (Lichtenstein) for inguinal hernia: $A$ study of 120 cases at Ghurki trust teaching hospital, Lahore. Pak J Med Health Sci. 2010; 4(3):223-5.

7. Nadir SM, Islam U, Ansari MA. An experience of mesh repair in inguinal hernia with two and half years follow up at civil hospital, Karachi. Pak J Surg. 2012; 28(4):271-5.

8. Lal K, Laghari ZH, Laghari A. Laparoscopic total extra peritoneal mesh repair and open Lichtenstein mesh repair for the treatment of inguinal hernia. Med Channel. 2011; 17(3):13-7.

9. Dahlstrand $U$, Sandblom G, Ljungdahl M, Wollert S, Gunnarsson $U$. TEP under general anesthesia is superior to Lichtenstein under local anesthesia in terms of pain 6 weeks after surgery: Results from a randomized clinical trial. Surg Endosc. 2013 Oct; 27(10):3632-8. doi: 10.1007/s00464-013-2936-1. Epub 2013 Apr 10. PubMed PMID: 23572220.

10. Messenger DE, Aroori S, Vipond MN. Five-year prospective follow-up of $\mathbf{4 3 0}$ laparoscopic totally extra peritoneal inguinal hernia repairs in 275 patients. Ann R Coll Surg Engl. 2010; 92(3):201-5.

11. Gürbulak EK, Gürbulak B, Akgün IE, Özel A, Akan D, Ömeroğlu S, Öz A, Mihmanlı M, Bektaş H. Effects of totally extra peritoneal (TEP) and Lichtenstein hernia repair on testicular blood flow and volume. Surgery. 2015 Nov; 158(5):1297-303. doi: 10.1016/j. surg.2015.03.028. Epub 2015 Apr 30. PubMed PMID: 25937159.

12. Aly $\mathrm{O}$, Green $\mathrm{A}$, Joy $\mathrm{M}$, Wong $\mathrm{CH}$, Al-Kandari $\mathrm{A}$, Cheng $S$, et al. Is laparoscopic inguinal hernia repair more effective than open repair? J Coll Physicians Surg Pak. 2011; 21(5):291-6.
13. Lal P, Bansal B, Sharma R, Pradhan G. Laparoscopic TEP repair of inguinal hernia does not alter testicular perfusion. Hernia. 2016 Jun; 20(3):429-34. doi: 10.1007/ s10029-016-1479-5. Epub 2016 Feb 29. PubMed PMID: 26924310.

14. Zhu X, Cao H, Ma Y, Yuan A, Wu X, Miao Y, Guo S (2014) Totally extra peritoneal laparoscopic hernioplasty versus open extra peritoneal approach for inguinal hernia repair: A meta-analysis of outcomes of our current knowledge. Surgeon 12:94-105.

15. Edwards CC, Bailey RW. Laparoscopic hernia repair: The learning curve. Surg Laparosc Endosc Percut Techn 2000; 10: 149-53.

16. Hamza Y, Gabr E, Hammadi H, Khalil R. Four-arm randomized trial comparing laparoscopic and open hernia repairs. Int J Surg. 2010; 8:25-8.

17. Bringman $S$, Ramel $S$, Heikkinen $T J$, Englund $T$, Westman B, Anderberg $B$. Tension-free inguinal hernia repair: TEP versus mesh-plug versus lichtenstein, a prospective randomized controlled trial. Ann Surg.2003; 237: 142-7.

18. Collaboration EH. Laparoscopic compared with open methods of groin hernia repair: Systematic review of randomized controlled trials. $\mathrm{Br} \mathrm{J}$ Surg 2000; 87: 860-7.

19. Dedemadi G, Sgourakis G, Radtke A, Dounavis A, Gockel I, Fouzas I, et al. Laparoscopic versus open mesh repair for recurrent inguinal hernia: A metaanalysis of outcomes. Am J Surg. 2010; 200:291-7.

20. Bhatti N, Abro AA, Shaikh B. Early outcome of laparoscopic total extra peritoneal inguinal hernia repair. Rawal Med J. 2014; 39:52-4.

21. Kulacoglu $\mathrm{H}$. Current options in inguinal hernia repair in adult patients. Hippokratia. 2011; 15(3):223-31.

\begin{tabular}{|c|c|c|c|}
\hline \multicolumn{4}{|c|}{ AUTHORSHIP AND CONTRIBUTION DECLARATION } \\
\hline Sr. \# & Author-s Full Name & Contribution to the paper & Author $=\mathbf{s}$ Signature \\
\hline 1 & Muhammad Usman & $\begin{array}{l}\text { Principal author, Main idea, Data } \\
\text { analysis \& result compilation. }\end{array}$ & \\
\hline 3 & Osman Riaz Dab & Reference collection. & calder \\
\hline 4 & Rana Asrar Ahmad Khan & Provision of data. & \\
\hline 5 & $\begin{array}{l}\text { Saddaqat Hayat } \\
\text { Ata UI Lateef }\end{array}$ & $\begin{array}{l}\text { Data analysis \& reference } \\
\text { collector. } \\
\text { Provision of data. }\end{array}$ & enew \\
\hline 6 & & Provision ot data. & \\
\hline
\end{tabular}

